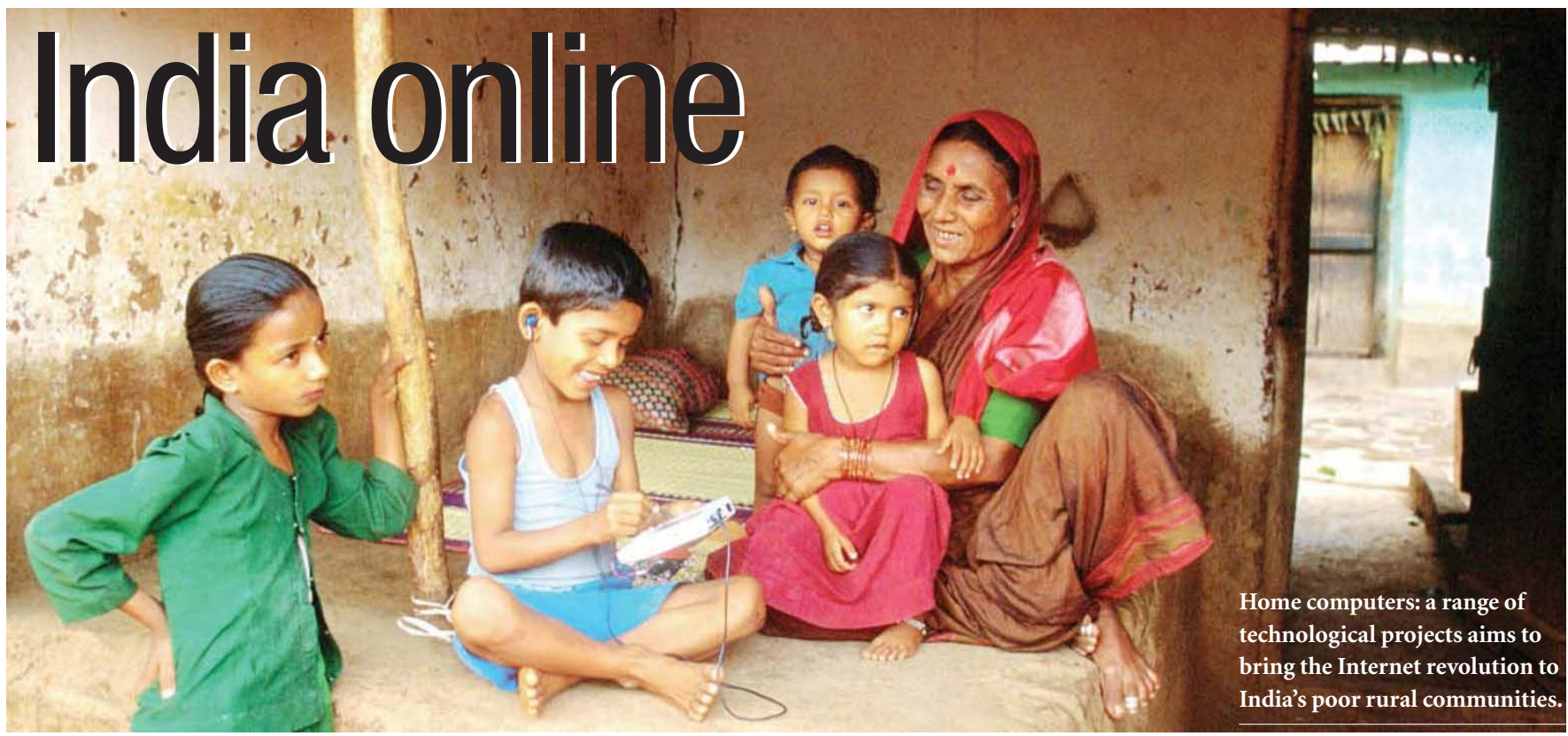

A limited telephone network and low levels of literacy make it difficult to get information technology into India's rural areas. But as K. S. Jayaraman finds out, the country's engineers have developed some innovative solutions.

$\mathrm{B}$ angalore may be the hub of a burgeoning information-technology industry, but the information superhighway peters out long before it reaches the villages of rural India. More than $80 \%$ of Indian villages have no telephone connection. Few villagers can afford computers where connections do exist, and low levels of literacy prevent many from using any machines they may have access to.

This is unfortunate, as villages have much to gain from the information revolution. Affordable Internet access could transform the way local farmers deal with wholesalers, or could supply health workers with reliable, up-to-date information. But because such ventures generate little or no profit, the big telecommunications operators and computer firms are unwilling to invest in them.

But India's problems are prompting Indian solutions. Engineers at one of the country's top research institutes are using radio links to get villages online. Others have developed an affordable computer that operates in three of India's most widely spoken languages. And both systems are designed to be attractive to local entrepreneurs and community organizations, thus bypassing the need for external investment.

"The big telecoms companies are ignoring the rural areas where $70 \%$ of Indians live," says P. G. Ponnapa, chief executive of telecoms company n-Logue, based in Chennai (formerly Madras). "Our aim is to bridge this digital divide."

It is easy to see why telecoms operators are reluctant to invest. New connections typically cost around US $\$ 800$ to install, and companies need a certain monthly return to justify such an investment. "Telecom networks are designed for people who can afford a \$30-40 monthly bill. Only $1.6 \%$ of Indians can pay this much," says Ashok Jhunjhunwala, head of an electrical-engineering group at the Indian Institute of Technology (IIT) in Chennai.

\section{The extra mile}

For around a decade, Jhunjhunwala's group has been working on cheaper systems, focusing on alternatives for the 'last-mile' connections between local exchanges and individual homes. Conventional networks use copper wires, which are expensive to install and maintain, and account for around threequarters of the cost of the entire network.

In conjunction with Analog Devices, a signal-processing company based in Norwood, Massachusetts, Jhunjhunwala's team has developed a wireless alternative, known as corDECT, which uses radio waves to link exchanges with homes. Existing telephone networks are used to carry signals over long distances. Once they reach the local exchange, however, the signals are digitized and beamed to homes and businesses, where a small, wallmounted device is used to receive them. By splitting voice and Internet traffic at the local exchange, the system provides a separate phone line with each Internet connection.

The system can reach subscribers in a 10-kilometre radius of the transmitter, or up to $25 \mathrm{~km}$ with the help of a solar-powered relay station. IIT researchers are looking at taking the system into areas where there is no nearby exchange by sending signals along the copper wires that run alongside the tracks of India's vast railway network. The system is normally used for voice communications, but includes spare wires that have not yet been used.

Several Indian companies, including n-Logue, a spin-off from the IIT, are already producing corDECT systems with connection speeds of 70 kilobits per second (kbps) faster than most home connections in richer countries. Another manufacturer, Midas Communication Technologies of Chennai, says it will soon offer 380 -kbps connections.

The technology is well-established, and is also being considered for use in Europe and the United States. But unlike in developed countries, its success will depend on small firms rather than big ones. Cable television, for example, has expanded rapidly thanks to local entrepreneurs. Broadcasters sell satel-

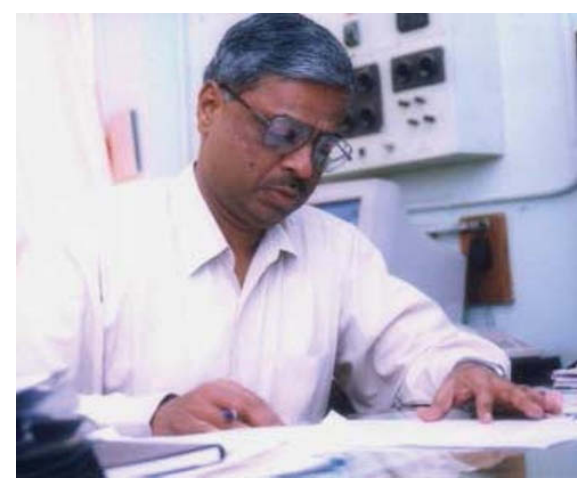

Ashok Jhunjhunwala has pioneered a cheap way to link homes to local telephone exchanges. 
